\title{
Estudo Comparativo entre as Redes Neurais Artificiais MLP e RBF para Previsão de Cheias em Curto Prazo
}

\author{
Daniel Gomes Soares ${ }^{1}$ \\ Raimundo Celeste Ghizoni Teive ${ }^{2}$ \\ Data de submissão: 03.02.2015 \\ Data de aceitação: 17.08.2015
}

\begin{abstract}
Resumo: Previsão de vazão ou dos níveis de um rio é um dos campos mais importantes da Hidrologia. A previsão em curto prazo do nível de um rio é uma das maneiras mais eficazes na diminuição dos impactos causados por eventos críticos de cheia. Esta pesquisa teve como objetivo a modelagem e validação de Redes Neurais Artificias (RNA) MLP e RBF para a previsão de cheias em curto prazo em um ponto do rio Itajaí-Açu localizado no município de Rio do Sul - SC, para posterior comparação dos resultados obtidos pelos modelos. O desempenho das RNAs é analisado através de três medidas estatísticas: CE (Coeficiente de Eficiência de Nash e Sutcliffe), RMSE (Root Mean Square Error) e MAPE (Mean Absolute Percentage Error). Os resultados indicam um desempenho satisfatório, tanto do MLP quanto da RBF para previsões com 6 horas de antecedência. Os resultados indicam também que a rede MLP obteve melhor desempenho, no entanto, a RBF também pode ser considerada uma alternativa viável para previsão de cheias em rios.
\end{abstract}

\begin{abstract}
Flow or levels of a river forecasting is one of the most important fields of Hydrology. The level of a river short term forecasting is one of the most effective ways in reducing the impacts of critical flood events. This research aimed to modeling and validation of artificial neural networks (ANN) MLP and RBF for flood forecasting in the short term at one point of Itajaí-Açu river in the municipality of Rio do Sul - SC. Afterwards, it was performed the comparison the results obtained from both models. The performance of RNAs is analyzed using three statistic measures: CE (Nash-Sutcliffe Coefficient), RMSE (Root Mean Square Error) e MAPE (Mean Absolute Percentage Error). The results indicate a satisfactory performance, both the MLP and the RBF, considering forecastings for 6 hours in advance. The results also show that the MLP is the model with the best performance, however, the RBF also can be considered a viable alternative to rivers flood forecasting .
\end{abstract}

\footnotetext{
${ }^{1}$ Laboratório de Inteligência Artificial, Instituto Federal Catarinense (IFC), Rua Abraham Lincoln, 210 - Jardim América - CEP: 89160-212 - Rio do Sul/SC, Brasil

\{danieleifc-riodosul.edu.br\}

2 UNIVALI, Rua Uruguai, 458 - Centro - CEP: 88302-202 - Itajaí/SC, Brasil \{rteive@univali.br\}
} 
Estudo Comparativo entre as Redes Neurais Artificiais MLP e RBF para Previsão de Cheias em Curto Prazo.

\section{Introdução}

Previsão de vazão ou dos níveis de um rio é um dos campos mais importantes da Hidrologia. A previsão em curto prazo do nível de um rio é uma das maneiras mais eficazes na diminuição dos impactos causados por eventos críticos de cheia [1]. O principal objetivo é prever as condições futuras do rio, em pontos vulneráveis à inundação, para emitir avisos de alerta à população residente nas áreas de risco [2].

$\mathrm{Na}$ última década, as Redes Neurais Artificias (RNA) tem se apresentado como uma técnica promissora para o desenvolvimento de modelos de previsão de vazão e nível de água em rios. Por meio dessa técnica, a dependência entre as variáveis de entrada e saída pode ser modelada por uma combinação de funções matemáticas não-lineares, o que pode levar a uma representação de sistemas complexos com uma precisão aceitável [3].

As RNAs são inspiradas no sistema nervoso biológico. Os neurônios artificiais são modelos simplificados dos neurônios biológicos, sendo que tais modelos foram inspirados a partir da análise da geração e propagação de impulsos elétricos pela membrana celular dos neurônios [4]. Uma das características mais importantes das RNAs é a sua capacidade de aprender por meio de exemplos. A etapa de aprendizagem consiste de um processo iterativo de ajustes dos pesos sinápticos, que ao final do processo guardam o conhecimento que a rede adquiriu do ambiente externo [5].

A principal vantagem das técnicas baseadas em RNA é a sua capacidade de modelar as relações de entrada-saída não-lineares, característica marcante dos processos hidrológicos, sem a necessidade de saber todos os detalhes dos processos físicos e suas interações. Estas qualidades toram as RNAs capazes de identificar e assimilar as características mais marcantes das séries hidrológicas, tais como sazonalidade, periodicidade e tendência, muitas vezes camufladas por ruídos [6,7].

As RNAs MLP (Multilayer Perceptron) e RBF (Radial Basis Function) são os tipos de rede que mais vem sendo utilizados na previsão hidrológica. Vários autores têm apresentado resultados satisfatórios na previsão de cheias 
Estudo Comparativo entre as Redes Neurais Artificiais MLP e RBF para Previsão de Cheias em Curto Prazo.

utilizando estas redes $[3,6,8,9,10]$, sendo que todos encontraram resultados melhores que os obtidos com outros modelos hidrológicos.

As RNAs do tipo MLP são caracterizadas por conterem pelo menos uma camada intermediária, ou escondida. Estas redes apresentam um poder computacional muito maior do que as redes sem camadas escondidas, pois possuem a capacidade de tratar dados que não são linearmente separáveis [11], como é o caso da previsão de cheias em rios. O algoritmo mais tradicional utilizado no treinamento de um MLP é denominado algoritmo de retropropagação do erro ou backpropagation.

A utilização do algoritmo backpropagation convencional na prática tende a convergir de forma demasiadamente lenta, exigindo-se assim um elevado esforço computacional. Algumas das alternativas para tornar o processo de convergência da rede mais eficiente são: a inserção do termo de momentum; ou a utilização de variantes do backpropagation como o algoritmo de Levenberg-Marquardt e a Regularização Bayesiana [4].

As redes denominadas funções de base radial, mais conhecidas como $\mathrm{RBF}$, podem ser utilizadas em praticamente todos os tipos de problemas tratados pelo MLP $[4,11]$. Mas ao contrário das redes MLP, que podem ser compostas por mais de uma camada oculta, a configuração típica da RBF é composta por apenas uma camada intermediária, na qual a função de ativação é de base radial, sendo a mais utilizada à função gaussiana.

Neste trabalho, modelos de RNAs MLP e RBF foram construídos para a previsão de cheias em um ponto do rio Itajaí-Açu, localizado na bacia do rio Itajaí, Santa Catarina - Brasil. As previsões foram realizadas com 6 horas de antecedência. $\mathrm{O}$ desempenho das RNAs é comparado com o objetivo de identificar qual o modelo e tipo de RNA é mais aderente a este tipo de aplicação. Para avaliar o desempenho das redes, três métricas foram utilizadas, coeficiente de eficiência (CE), root mean square error (RMSE) e mean absolute square error (MAPE).

\section{2 Área de Estudo e Dados Disponíveis}

A bacia hidrográfica do rio Itajaí, está localizada na vertente atlântica do Estado de Santa Catarina, entre as coordenadas $26^{\circ} 22^{\prime}$ e $27^{\circ} 53^{\prime}$ de latitude 
Estudo Comparativo entre as Redes Neurais Artificiais MLP e RBF para Previsão de Cheias em Curto Prazo.

sul e $48^{\circ} 30^{\prime}$ e $50^{\circ} 22^{\prime}$ de longitude oeste. Esta é a maior bacia da vertente atlântica do Estado de Santa Catarina, abrangendo uma área de aproximadamente $15.000 \mathrm{~km}^{2}$, sendo dividida em três compartimentos naturais: o Alto, o Médio, e o Baixo Vale do Itajaí. O maior curso d'água da bacia é o rio Itajaí-Açu, formado pela junção dos rios Itajaí do Oeste e Itajaí do Sul, no munícipio de Rio do Sul [12]. O Vale do Itajaí é mostrado na Figura 1.

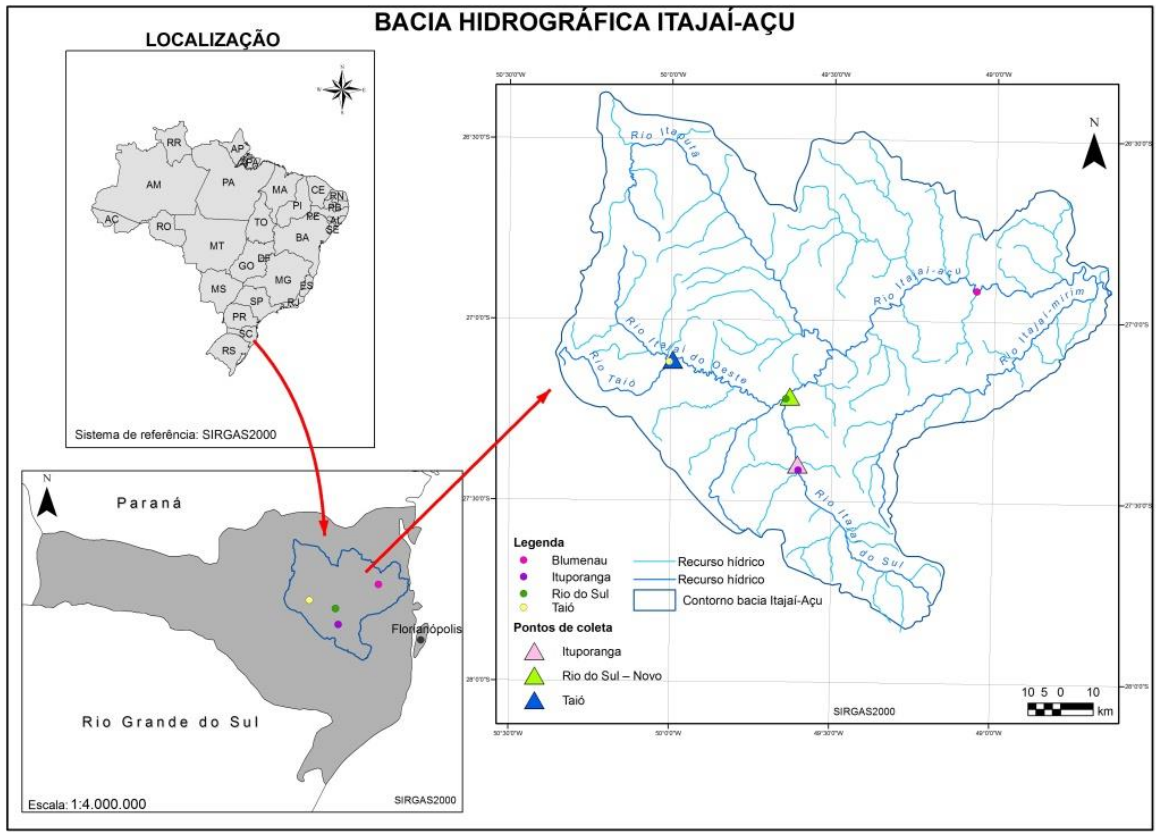

Figura 1.Vale do Itajaí - SC

O local selecionado para as previsões de cheias, está localizado no Alto Vale do Itajaí, no município de Rio do Sul. Segundo Cordero, Momo e Severo [13], Rio do Sul se encontra entre a Serra do Mar e a Serra Geral e sua população é de cerca de 60.000 habitantes. A área de drenagem da bacia é de aproximadamente $5.100,00 \mathrm{~km}^{2}$ até a estação fluviométrica de Rio do Sul. A precipitação pluviométrica total anual pode variar de 1.320 a $1.640 \mathrm{~mm}$, com o total anual de dias de chuva entre 130 e 165 dias. 
Estudo Comparativo entre as Redes Neurais Artificiais MLP e RBF para Previsão de Cheias em Curto Prazo.

O convívio com as cheias do rio Itajaí-Açu e consequentemente os problemas causados por estas, são registrados desde os primeiros povoamentos na região, por volta de 1850 . Os registros históricos indicam a região como um cenário expressivo para ocorrência de eventos de inundação. $\mathrm{Na}$ cidade de Rio do Sul foram registrados diversos desses eventos no decorrer da sua história, há registros de grandes inundações nos anos de 1927 (12m), 1954 (11,84m), 1983 (15,08m), 1984 (13,64m), 2011 (12,98m), 2013 $(10,32 \mathrm{~m})$ e $2015(10,71 \mathrm{~m})$.

Os dados disponíveis na bacia do rio Itajaí são registrados pela rede telemétrica da Agência Nacional de Águas (ANA), e operadas pela Empresa de Pesquisa Agropecuária e Extensão Rural de Santa Catarina (Epagri). Os dados foram obtidos das estações de medição localizadas nos municípios Ituporanga, Taió e Rio do Sul, sendo os dados dos dois primeiros postos utilizados como entradas (nível do rio e precipitação para ambas entradas) e nível do rio em Rio do Sul como saída. A localização das estações de medição é mostrada na Figura 1.

Uma característica importante da bacia é o tempo de deslocamento da onda de cheia na rede de drenagem, ou seja, o tempo que a água leva para ir dos postos de medição a montante do ponto de interesse até a área selecionada para realizar as previsões. Este tempo de deslocamento é de 6 horas entre o posto localizado no munícipio de Ituporanga e Rio do Sul, e de 8 horas de Taió à Rio do Sul. Realizar previsões entre 6 e 8 horas de antecedência já é útil para ações da Defesa Civil.

Os dados utilizados nos treinamentos e testes das RNAs estão no intervalo entre 08/2005 e 02/2014. Estes dados foram obtidos no Sistema de Informações Hidrológicas (Hidroweb) da ANA.

\section{Métodos}

\subsection{Rede Neural Artificial proposta}

Neste trabalho RNAs do tipo MLP e RBF foram modeladas para previsão de cheias em curto prazo. Estas redes foram construídas com quatro entradas, uma camada oculta com $n$ neurônios, com $n$ variando entre 3 e 10, e um neurônio na camada de saída (ver Figura 2). A opção pela utilização de 
Estudo Comparativo entre as Redes Neurais Artificiais MLP e RBF para Previsão de Cheias em Curto Prazo.

uma camada oculta e de até 10 neurônios nesta camada foi definida após a realização de alguns testes preliminares, em que se observou que o uso de mais do que uma camada e, mais de 10 neurônios nesta mesma camada, não produzia melhoras significativas nos resultados, apenas aumentava significativamente o tempo de treinamento.

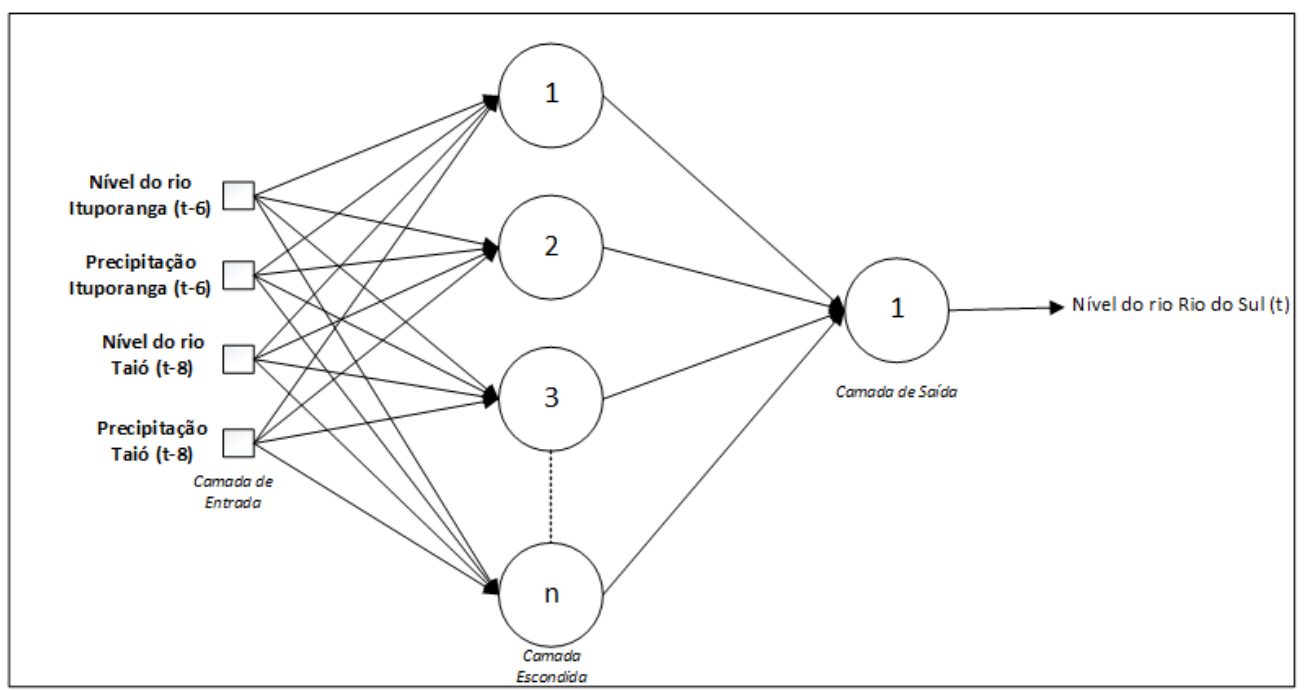

Figura 2. Modelo de RNA proposto

As redes neurais utilizadas nesta pesquisa foram construídas, treinadas e testadas utilizando-se o toolbox de Redes Neurais do software Matlab. Dessa forma, a nomenclatura adotada para as funções de ativação e algoritmos de treinamento foi a mesma usada pelo software.

As funções de ativação utilizadas na camada escondida do MLP foram a TANSIG (sigmoide tangente hiperbólica) e LOGSIG (sigmoide logística). Nas RNAs RBF, que tem como característica funções de ativação de base radial, na camada escondida foi utilizada a função radbas (base radial). $\mathrm{Na}$ camada de saída das RNAs foi utilizada a função PURELIN (linear).

Em geral, os algoritmos de treinamento são sofisticações do método de treinamento da retropropagação do erro, que melhoram a rapidez do treinamento, a capacidade de generalização, ou evitam o sobreajuste [14]. Dessa forma, os algoritmos utilizados neste trabalho foram o TrainGDM 
Estudo Comparativo entre as Redes Neurais Artificiais MLP e RBF para Previsão de Cheias em Curto Prazo.

(Gradiente Descendente com momentum), TrainLM (Levenberg-Marquardt) e TrainBR (Regularização Bayesiana), os quais estão disponíveis no toolbox de Redes Neurais do software Matlab

\section{2 Índices para análise da qualidade da previsão}

O desempenho da RNA pode ser medido por diferentes termos de eficiência, que são calculados a partir dos valores previstos e as metas (ou valores medidos) [15]. Os índices para a avalição da qualidade da previsão utilizados neste trabalho foram o CE, RMSE e MAPE.

O Coeficiente de Eficiência de Nash e Sutcliffe (CE) é definido por:

$$
C E=1-\frac{\sum_{i=1}^{n}\left(Q o_{i}-Q p_{i}\right)^{2}}{\sum_{i=1}^{n}\left(Q o_{i}-\overline{Q o}\right)^{2}}
$$

onde $Q o_{i}$ representa o valor observado, $Q p_{i}$ o valor previsto e $\overline{Q o}$ o valor médio dos valores observados.

O RMSE (Root Mean Square Error) é definido por:

$$
R M S E=\sqrt{\frac{\sum\left(Q_{o b s}-Q_{c a l}\right)^{2}}{N}}
$$

onde $Q_{o b s}$ representa o valor observado, $Q_{c a l}$ o valor previsto pela rede e $N$ o número de pontos utilizados no treinamento.

O MAPE (Mean Absolute Percentage Error) é definido por:

$$
M A P E=\frac{\sum_{t=1}^{n}\left|E P_{t}\right|}{n}
$$

onde $\left|E P_{t}\right|$ representa o módulo do erro médio percentual e $n$ o número de pontos utilizados no treinamento.

Em geral, o desempenho do modelo de previsão é considerado bom quando o CE, RMSE e MAPE estão perto de 1, 0, 0, respectivamente. 
Estudo Comparativo entre as Redes Neurais Artificiais MLP e RBF para Previsão de Cheias em Curto Prazo.

\subsection{Definição da melhor configuração de RNA}

As RNAs possuem múltiplos parâmetros de ajuste, que modificam suas características e consequentemente levam a rede a produzir resultados diversos em cada treinamento realizado. Alguns parâmetros foram alterados, como a função de ativação, o número de neurônios na camada escondida, o algoritmo de treinamento e o spread (este último somente na RBF). Alguns foram mantidos constantes em todos os treinamentos, como por exemplo, o número máximo de épocas. Porém, outros foram deixados totalmente aleatórios, tais como os pesos iniciais dos neurônios e a seleção das amostras dos conjuntos de treinamento e teste. Dentro desse contexto, a escolha da melhor configuração foi efetuada em duas fases, que serão descritas a seguir.

$\mathrm{Na}$ primeira fase, uma mesma configuração de RNA, por exemplo, MLP com 3 neurônios na camada intermediária, função de ativação TANSIG e algoritmo de treinamento TrainGDM, foi treinada 30 vezes, de modo a minimizar os efeitos causados pela aleatoriedade das condições iniciais. Dessa forma, após uma configuração específica de RNA ser treinada 30 vezes, foi escolhido o ensaio que possuía o menor RMSE, menor MAPE e maior CE. Essa mesma sistemática foi repetida para todas as redes construídas.

Em seguida, na segunda fase, RNAs com configurações diferentes, por exemplo, diferentes algoritmos de treinamento, quantidade de neurônios na camada escondida e função de ativação, são comparadas entre si com o objetivo de identificar, novamente, a rede com menor RMSE, menor MAPE e maior CE. Assim, após execução das duas fases foi possível identificar o tipo (MLP ou RBF) e configuração de RNA, mais aderente à área de estudo selecionada.

\section{Resultados e Discussão}

Um total de 416 RNAs MLP foram testadas, os parâmetros alterados em cada alternativa foram o número de neurônios na camada oculta, que foi entre 3 e 10, a função de ativação da camada oculta (TANSIG e LOGSIG) e o algoritmo de treinamento (TrainLM, TrainBR e TrainGDM). Alguns testes foram realizados com mais de 10 neurônios na camada intermediária, no entanto, a rede não produzia melhoras significativas nos resultados, 
aumentando de maneira considerável o tempo de treinamento. No caso específico do algoritmo de treinamento TrainGDM, após este algoritmo apresentar resultados com erros consideravelmente maiores em comparação com os outros dois algoritmos utilizados, novos testes foram realizados alterando-se além dos parâmetros descritos acima, os valores de momentum e taxa de aprendizagem. Na Tabela 1 é apresentado o número de redes MLP treinadas usando cada algoritmo.

Tabela 1. Número de redes MLP treinadas por cada algoritmo.

\begin{tabular}{cc}
\hline Algoritmo & $\mathbf{N}^{\mathbf{0}} \mathbf{R N A s}$ \\
\hline TrainLM & 16 \\
TrainBR & 16 \\
TrainGDM & 384 \\
\hline Total MLPs & 416 \\
\hline
\end{tabular}

$\mathrm{O}$ ajuste dos pesos e bias durante o treinamento foi realizado conforme a função de desempenho escolhida, que no caso deste trabalho manteve a função padrão do Matlab o erro quadrático médio (MSE), calculado a partir da saída produzida pela rede e as saídas desejadas (targets).

No caso das RNAs RBF, 14 alternativas foram testadas. A função que cria este tipo de rede no Matlab (newrb), não permite a definição do número de neurônios na camada escondida, podendo somente ser estipulado o número máximo. Os parâmetros utilizados para criação da rede RBF através do comando newrb(P, T, goal, spread, $M N)$ foram os seguintes:

Matriz de vetores de entrada $(P)$

Matriz de vetores de saída $(T)$

Erro médio quadrático pretendido (goal)

Raio da função de base radial (spread)

Número máximo de neurônios na camada oculta $(M N)$

O spread é um dos parâmetros que influencia de maneira mais significativa nos resultados produzidos pela $\mathrm{RBF}$, por isso, diferentes valores deste parâmetro foram testados no intervalo entre 0.1 e 3 . 
Estudo Comparativo entre as Redes Neurais Artificiais MLP e RBF para Previsão de Cheias em Curto Prazo.

\subsection{Resultados MLP}

Os resultados produzidos pelas três melhores MLPs quando apresentadas ao conjunto de testes são apresentados na Tabela 2. A configuração das RNAs é identificada na primeira coluna da tabela, através da seguinte definição de siglas:

(i)N: RNA com "i”" neurônios na camada oculta;

Tan: função TANSIG na camada oculta;

Log: função LOGSIG na camada oculta;

LM, BR: algoritmos de treinamento TrainLM e TrainBR respectivamente.

Tabela 2. Desempenho das melhores configurações MLP

\begin{tabular}{cccc}
\hline Modelo & CE & RMSE & MAPE \\
\hline 6N_Log_BR & 0,9788 & 0,0202 & 5,8024 \\
9N_Log_LM & 0,9779 & 0,0201 & 5,7625 \\
9N_Tan_BR & 0,9776 & 0,0199 & 5,7982 \\
\hline
\end{tabular}

O maior $\mathrm{CE}(0,9788)$ foi obtido pela configuração treinada com 6 neurônios, função de ativação LOGSIG e o algoritmo TrainBR. No entanto, nos outros índices utilizados duas RNAs com 9 neurônios na camada oculta obtiveram melhores resultados. A rede treinada com o algoritmo TrainLM e função de ativação LOGSIG obteve menor MAPE $(5,7625)$, e a rede treinada com o algoritmo TrainBR e função TANSIG obteve o menor RMSE $(0,0199)$. Excluindo o índice $\mathrm{CE}$, as RNAs com 9 neurônios obtiveram melhores resultados em comparação com a rede de 6 neurônios nas outras duas métricas (RMSE e MAPE em ambas). Portanto levando-se em consideração os três índices utilizados, as redes com maior complexidade (com 9 neurônios na camada oculta) apresentaram melhores desempenhos e maior poder de generalização, que a rede com menor $\mathrm{CE}$ e as redes de menor complexidade no geral. 
Estudo Comparativo entre as Redes Neurais Artificiais MLP e RBF para Previsão de Cheias em Curto Prazo.

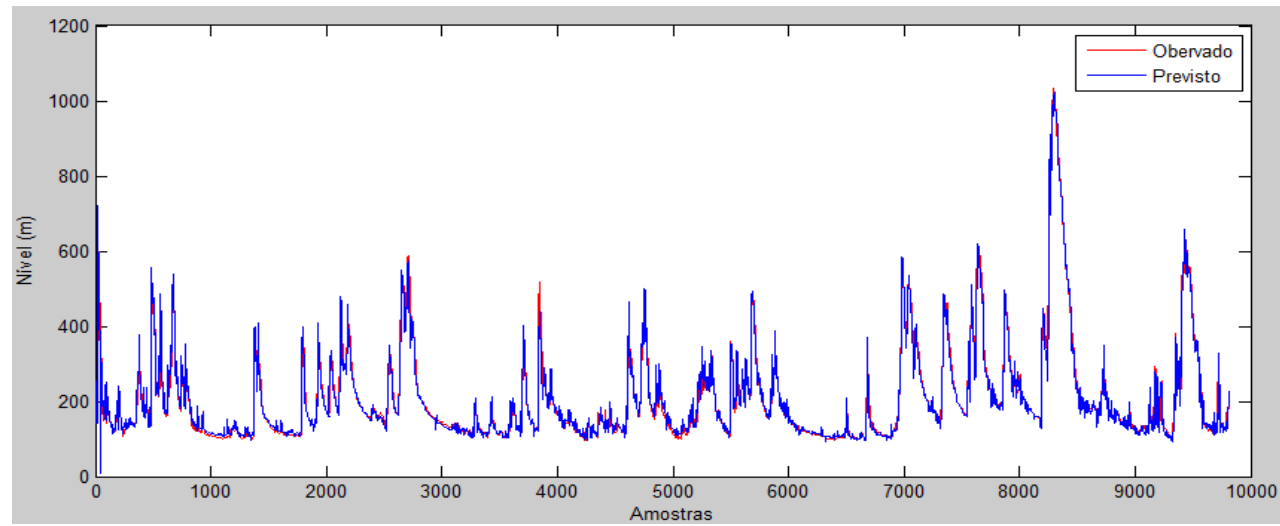

Figura 3. Gráfico do nível previsto e observado da MLP 6N_Log_BR que obteve o maior CE

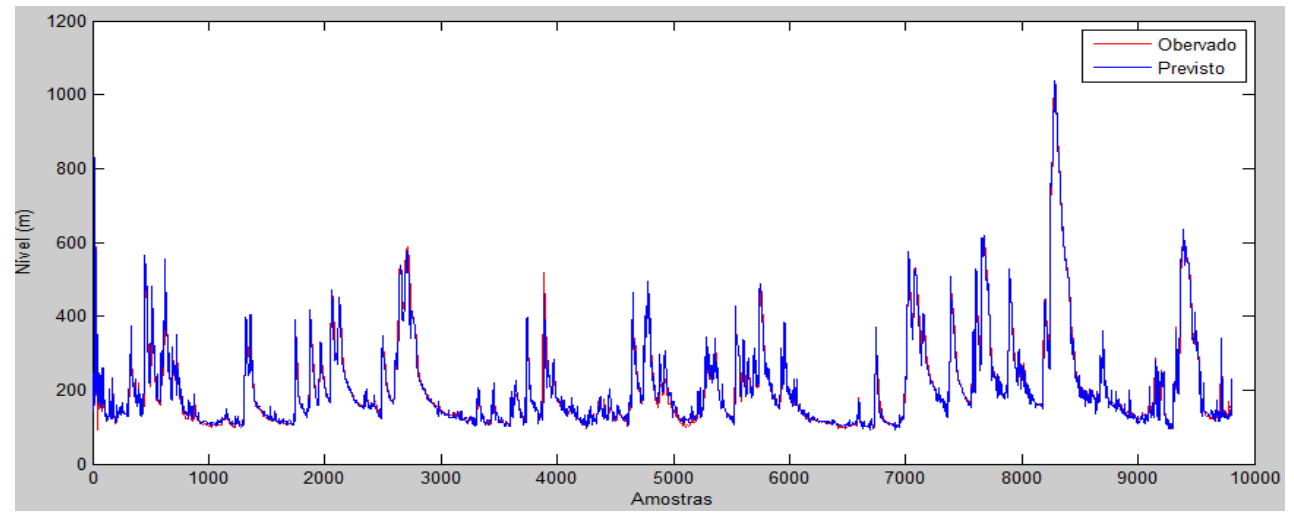

Figura 4. Gráfico do nível previsto e observado da MLP 9N_Tan_BR que obteve o menor RMSE

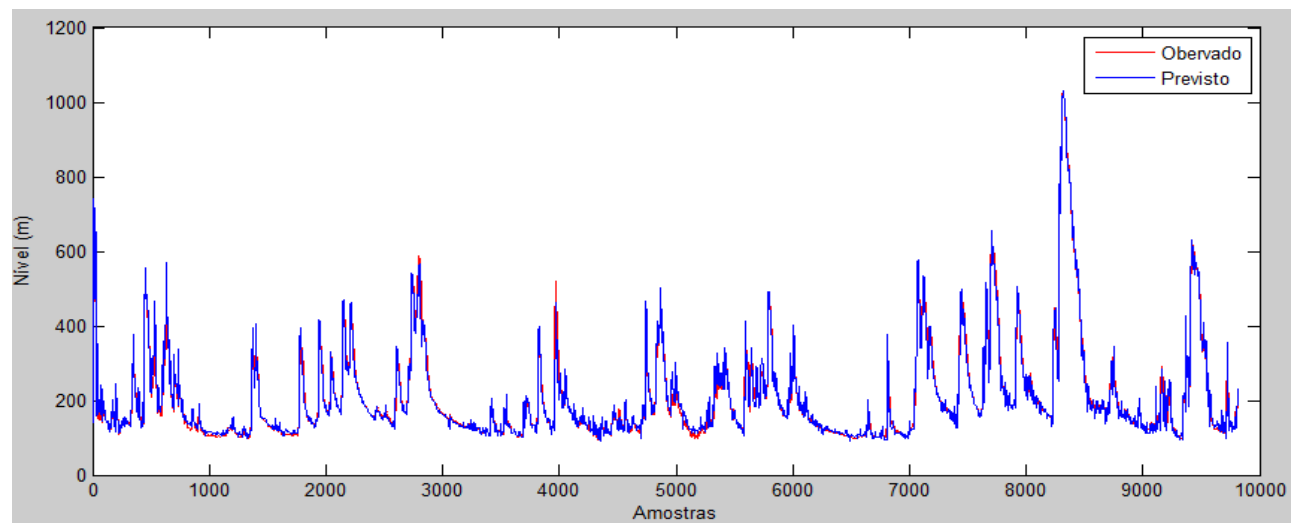

Figura 5. Gráfico do nível previsto e observado da MLP 9N_Log_LM que obteve o menor MAPE 
Estudo Comparativo entre as Redes Neurais Artificiais MLP e RBF para Previsão de Cheias em Curto Prazo.

Na Figura 3 são apresentados os níveis previstos e observados da rede que obteve o maior $\mathrm{CE}$. As maiores diferenças ocorreram em alguns níveis calculados em torno de 4 metros, onde o modelo calculou valores menores que os observados. No entanto, o maior interesse deste trabalho são as previsões de nível de água alto, que no caso da região de estudo selecionada são os níveis acima de 6,5 metros. Para esta faixa, os valores calculados e observados estão com praticamente nenhuma diferença.

Assim como a rede 6N_Log_BR, a rede 9N_Tan_BR, também produziu resultados muito parecidos com os níveis observados, conforme a Figura 4. A mesma imprecisão em alguns níveis calculados em torno de 4 e 5 metros também pode ser observada nesta rede. Entretanto, para valores de nível de água alto, os níveis previstos e observados estão muito próximos.

$\mathrm{Na}$ Figura 5 podem ser vistos os níveis previstos e observados da rede que obteve o menor MAPE (9N_Log_LM). Assim como nas duas outras RNAs que obtiveram os melhores CE e RMSE (Figura 3 e Figura 4), imprecisões para alguns níveis calculados no intervalo entre 4 e 5 metros também ocorreram, mas para os valores de nível de água alto, ponto de interesse deste trabalho, a diferença entre observado e calculado foi praticamente nenhuma.

Embora, no geral, as RNAs testadas apresentarem bons resultados, comparando as redes com os melhores desempenhos, as alternativas com 9 neurônios na camada oculta apresentaram resultados ligeiramente superiores que a rede com 6 neurônios na camada oculta (6N_Log_BR). Na comparação entre as duas redes com 9 neurônios, a rede 9N_Log_LM obteve melhor CE $(0,9779)$ e o menor MAPE $(5,7628)$, enquanto que a rede $9 \mathrm{~N}$ Tan_BR obteve somente o melhor RMSE (0,0199). Dessa forma, a rede MLP que produziu os resultados com menores erros de acordo com as métricas utilizadas, foi a rede com 9 neurônios na camada oculta, função de ativação LOGSIG e algoritmo de treinamento TrainLM.

A regressão linear do MLP com melhor desempenho (9N_Log_LM) entre os valores observados (reais) e valores previstos, indicam uma forte correlação entre o modelo da RNA e o problema real, conforme pode ser observado na Tabela 3. Nesse caso considerou-se 9810 observações do nível do rio. 
Estudo Comparativo entre as Redes Neurais Artificiais MLP e RBF para Previsão de Cheias em Curto Prazo.

Tabela 3. Estatística de Regressão da RNA MLP 9N_Log_LM

\begin{tabular}{cc}
\hline \multicolumn{2}{c}{ Estatística de Regressão } \\
\hline R-múltiplo & 0,988906 \\
R-Quadrado & 0,977934 \\
R-quadrado ajustado & 0,977932 \\
Erro padrão & 19,17105 \\
Observações & 9810 \\
\hline
\end{tabular}

Portanto, como a análise de regressão apontou uma correlação muito forte entre o modelo previsor, baseado em RNA, e o sistema do rio, ficou demonstrado a significância estatística dos dados utilizados pela rede MLP de melhor desempenho.

\subsection{Resultados RBF}

Dentre todas as configurações de RBFs modeladas duas obtiveram os melhores resultados quando apresentadas ao conjunto de testes. Os resultados são apresentados na Tabela 4.

Tabela 4. Resultados melhores configurações RBF

\begin{tabular}{ccccc}
\hline $\mathbf{N}^{\mathbf{0}}$ neurônios & Spread & $\mathbf{C E}$ & RMSE & MAPE \\
\hline 62 & 0,1 & 0,9628 & 0,039 & 4,5323 \\
69 & 0,2 & 0,9633 & 0,0383 & 4,7089 \\
\hline
\end{tabular}

O maior $\operatorname{CE}(0,9633)$ e menor $\operatorname{RMSE}(0,0383)$ foram obtidos pela mesma rede, treinada com spread 0,2 e com 69 neurônios na camada oculta. Já o menor MAPE $(4,5323)$ foi obtido pela rede treinada com spread 0,1 e 62 neurônios na camada oculta.

Os resultados dos valores de nível do rio calculados e observados, para as duas redes que obtiveram os melhores CE, RMSE e MAPE, dentre todas as alternativas de RBF testadas, são apresentados nas Figuras 6 e 7, respectivamente. 
Estudo Comparativo entre as Redes Neurais Artificiais MLP e RBF para Previsão de Cheias em Curto Prazo.

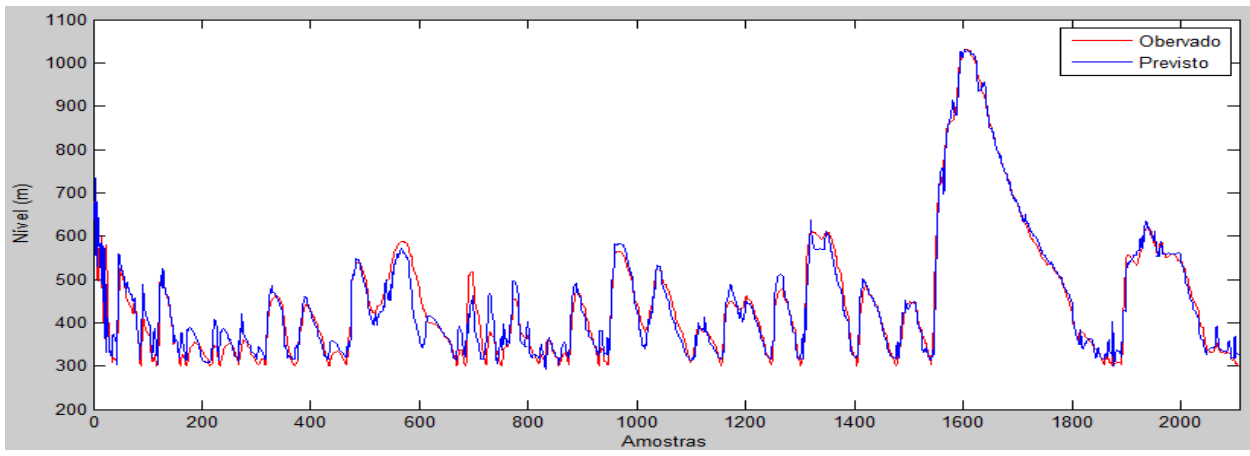

Figura 6. Gráfico do nível previsto e observado da RBF que obteve o maior CE e menor RMSE

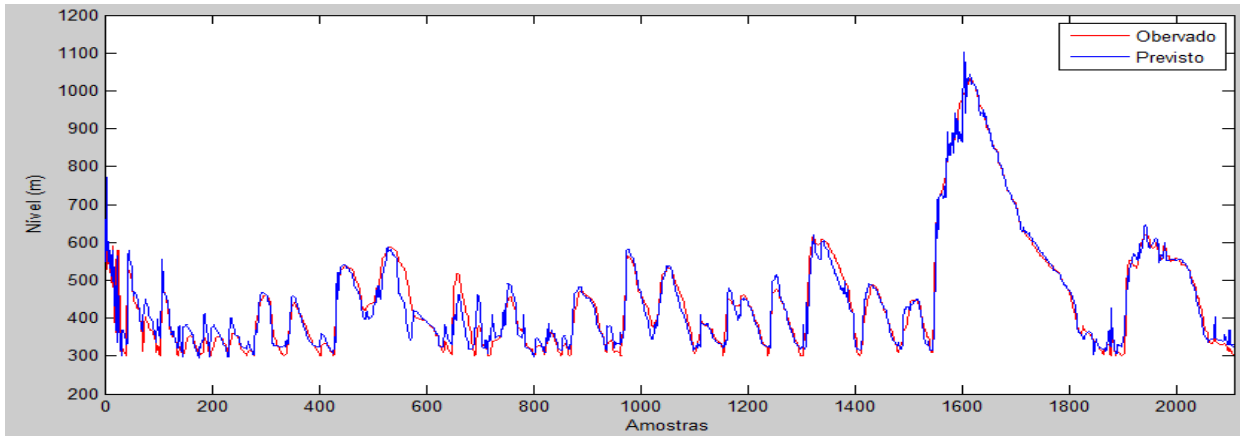

Figura 7. Gráfico do nível previsto e observado da RBF que obteve o menor MAPE

Conforme pode ser observado na Figura 6, os níveis calculados foram muito próximos dos observados, principalmente nos níveis de água alto, no qual a diferença entre os níveis produzidos pelo modelo e os observados foi praticamente nenhuma. Os resultados de nível do rio calculado e observado também foram muito próximos na RBF que obteve o menor MAPE $(4,5323)$. No entanto, para alguns valores de nível de água alto o modelo previu valores menores que os níveis observados, conforme pode ser observado na Figura 7.

Praticamente todas as alternativas de RBF testadas apresentaram bons resultados, com CE acima de 0.95 e MAPE abaixo de 5\%, em quase todas as alternativas. A única configuração que não alcançou o MAPE abaixo de 5\% foi a rede treinada com o valor de spread igual a 3, maior spread dentre todas as RBFs treinadas, que também obteve o pior RMSE. 
A rede com spread de 0.2 e 69 neurônios na camada oculta é a melhor configuração de RBF dentre todas as alternativas treinadas e testadas nesta pesquisa. A superioridade desta rede em relação às outras, fica evidente não só através dos melhores resultados nas métricas CE $(0,9633)$ e RMSE $(0,0383)$, mas também pode ser observado graficamente na Figura 6, com os valores de nível do rio calculado e observado muito próximos, ao contrário da rede com melhor MAPE, que não previu satisfatoriamente (Figura 7) valores de nível de água alto.

A regressão linear da rede RBF com melhor desempenho (spread 0.2) entre os valores observados (reais) e valores previstos, indicam uma forte correlação entre o modelo previsor e o problema real, conforme pode ser observado na Tabela 5. Nesse caso considerou-se 2107 observações do nível do rio.

Tabela 5. Estatística de regressão da melhor configuração de RBF

\begin{tabular}{cc}
\hline \multicolumn{2}{c}{ Estatística de Regressão } \\
\hline R-múltiplo & 0,981469 \\
R-Quadrado & 0,963282 \\
R-quadrado ajustado & 0,963265 \\
Erro padrão & 28,16851 \\
Observações & 2107 \\
\hline
\end{tabular}

Portanto, assim como na melhor MLP, a análise de regressão apontou uma correlação muito forte entre o modelo previsor, baseado em RNA, e o sistema do rio, demonstrado, dessa forma, a significância estatística dos dados utilizados pela rede RBF de melhor desempenho.

\subsection{Escolha da melhor configuração de RNA}

A melhor configuração de MLP, ou seja, a rede que produziu os resultados com menores erros, foi a alternativa com 9 neurônios na camada oculta, função de ativação LOGSIG e algoritmo de treinamento TrainLM. Esta rede obteve o melhor desempenho, dentre todas as redes MLP construídas, se analisadas as três métricas utilizadas CE, RMSE e MAPE, 
Estudo Comparativo entre as Redes Neurais Artificiais MLP e RBF para Previsão de Cheias em Curto Prazo.

com valores de $0,9779,0,0201$ e 5,7625, respectivamente. Por outro lado, a RBF com melhor desempenho foi a rede com spread de 0.2 , função de ativação radbas e 69 neurônios na camada oculta. Analisados os três parâmetros estatísticos CE, RMSE e MAPE, esta rede obteve o melhor desempenho, dentre as RBFs, com valores de 0,9633, 0,383 e 4,7089, respectivamente.

$\mathrm{Na}$ comparação entre as duas redes com resultados mais satisfatórios, levando-se em consideração as três métricas de erro utilizadas, a rede MLP obteve melhor desempenho em duas métricas, CE e RMSE, tendo um desempenho pior que a rede RBF somente na métrica MAPE. Portanto, na comparação entre as duas redes, tendo-se como parâmetro de comparação as métricas de erro, a RNA MLP obteve melhor desempenho que a RBF.

Como forma de também avaliar qual das duas redes obteve melhor desempenho, na Tabela 6 são apresentados os níveis calculados pelas redes em comparação com alguns valores observados. Optou-se por selecionar valores de nível do rio alto, pois são as previsões de maior interesse deste trabalho.

Tabela 6. Previsões realizadas pelas melhores configurações de MLP e RBF

\begin{tabular}{cccccc}
\hline Data & $\begin{array}{c}\text { Nível Rio do Sul } \\
(\mathbf{c m})\end{array}$ & $\begin{array}{c}\text { MLP } \\
(\mathbf{c m})\end{array}$ & $\begin{array}{c}\text { Erro MLP } \\
(\mathbf{c m})\end{array}$ & $\begin{array}{c}\text { RBF } \\
(\mathbf{c m})\end{array}$ & $\begin{array}{c}\text { Erro RBF } \\
(\mathbf{c m})\end{array}$ \\
\hline $01 / 09 / 2005$ & 699 & 697,96 & 1,04 & 550,35 & 148,65 \\
$05 / 09 / 2005$ & 723 & 742,05 & 19,05 & 501,76 & 221,24 \\
$23 / 09 / 2013$ & 1032 & 1033,41 & 1,41 & 1019,28 & 12,72 \\
$24 / 09 / 2013$ & 1031 & 1030,96 & 0,04 & 1041,42 & 10,42 \\
$13 / 01 / 2014$ & 621 & 628,63 & 7,63 & 472,75 & 148,25 \\
\hline
\end{tabular}

Conforme pode ser observado na Tabela 6 , os níveis calculados pela rede MLP estão mais próximos dos níveis observados que os valores calculados pela RBF. Os níveis calculados pela MLP apresentaram uma diferença de poucos centímetros em relação aos dados observados. Já os valores calculados pela $\mathrm{RBF}$ apresentaram uma diferença maior, em alguns casos maiores que 1 metro, o que é uma diferença considerável em se tratando de cheias na região de estudo. Todos os níveis apresentados na 
Tabela 6 são considerados altos, ou seja, pelo menos alguma região da cidade foi alagada, no entanto, para os dois níveis de rio mais altos apresentados na Tabela 6, tanto a MLP como a RBF produziram resultados muito próximos, com poucos centímetros de diferença para o valor observado. Mas apesar dos valores próximos entre calculado e observado da RBF para os dois níveis mais altos, a rede MLP calculou os níveis mais próximos dos valores medidos em todos os níveis apresentados na Tabela 6.

Portanto, analisando as métricas de erro CE, RMSE e MAPE e os resultados apresentados na Tabela 6 , chega-se a conclusão que a RNA mais aderente a área de estudo, ou seja, a rede com melhor desempenho dentre todas as construídas, treinadas e testadas, é a rede MLP (9N_Log LM) com 9 neurônios na camada oculta, função de ativação LOGSIG e algoritmo de treinamento TrainLM.

Os resultados apresentados pela rede 9N_Log_LM demonstram que é possível fazer a previsão de cheias em curto prazo na área de interesse, utilizando RNAs e que o tipo de RNA mais indicado é o MLP, conforme pode ser observado na análise dos resultados. No entanto, a rede RBF também pode ser considerada uma alternativa viável para previsão de cheias em curto prazo.

\section{Conclusões}

Este pesquisa se propôs a comparar RNAs MLP e RBF para a previsão de cheias em curto prazo, numa área específica. A área de estudo escolhida foi o município de Rio do Sul - SC, que possui um extenso histórico de cheias, inclusive recentes $(2011,2013$ e 2015).

Um total de 430 configurações de RNAs MLP e RBF foram construídas. $\mathrm{O}$ melhor desempenho dentre todas as configurações foi o da rede MLP 9N_Log_LM, com 9 neurônios na camada oculta, função de ativação logística e algoritmo de treinamento TrainLM. Esta rede produziu as previsões de melhor qualidade dentre todas as RNAs modeladas com CE, RMSE e MAPE de 0.9779, 0.0201 e 5.625, respectivamente.

Apesar da rede 9N_Log_LM ter obtido o melhor desempenho, no geral, praticamente todas as alternativas construídas apresentaram bons resultados 
Estudo Comparativo entre as Redes Neurais Artificiais MLP e RBF para Previsão de Cheias em Curto Prazo.

com CE acima de 0.95, RMSE próximo de 0 e MAPE abaixo de $6 \%$, demonstrando a eficiência e a aplicabilidade das RNAs MLP e RBF neste tipo de problema, principalmente em regiões com poucos dados disponíveis, como é o caso da região de estudo deste trabalho, onde não é possível a utilização de modelos mais sofisticados e que necessitam de um elevado número de parâmetros para serem calibrados.

A principal limitação das RNAs do tipo MLP e RBF quando aplicadas a este tipo de problema, decorre do empirismo em sua formulação, podendo errar muito para eventos com características não-lineares que não foram representados no ajuste, ou considerados no treinamento, ou seja, a extrapolação de cenários em alguns casos não é tão eficiente para estas redes. Nesse caso, enquanto não houver eventos extremos, que não foram considerados no treinamento, a rede continua ajustada ao problema, caso contrário, o modelo deverá ser atualizado.

Cabe destacar que não ficou evidenciado nos testes realizados, nenhuma tendência dos valores previstos, tanto para o modelo de RNA MLP, quando para a rede RBF, serem acima ou abaixo dos valores observados na estação de Rio do Sul, ponto de interesse das previsões. Em alguns testes, ambos modelos previram acima e em outros previram abaixo dos dados reais, não caracterizando nenhuma tendência nesse sentido.

\section{Referências}

[1]KANT, A., SUMAM, P. K., GIRI, B. K., TIWARI, M. K., CHATTERJEE, C., NAYAK, P. C., KUMAR, S. Comparison of multiobjective evolutionary neural network, adaptive neuro-fuzzy inference system and bootstrap-based neural network for flood forecasting. Neural Computing and Applications. 2013,doi:10.1007/s00521-013-1344-8

[2] MELlER, A., BRAVO, J. M., COLlischONN, W. Assimilação de Dados de Vazão na Previsão de Cheias em Tempo-Real com o Modelo Hidrológico MGB-IPH. Revista Brasileira de Recursos Hídricos. v. 17, p. 209-224, 2012. 
Estudo Comparativo entre as Redes Neurais Artificiais MLP e RBF para Previsão de Cheias em Curto Prazo.

[3] FREITAS, M. C., SILVA, G. B. L. Estimativa de vazões diárias em rios a partir de vazões a montante usando Redes Neurais Artificiais. XIX Simpósio Brasileiro de Recursos Hídricos. Maceió, 2011.

[4] SILVA, I.N., SPATTI, D., e FLAUZINO, R. A. Redes neurais artificiais para engenharia e ciências aplicadas: curso prático. Artliber Editora Ltda, São Paulo, 2010.

[5] BRAGA, A., P; CARVAlho, A., P., L; LUDERMIR, T., B. Redes Neurais Artificiais: Teoria e Aplicações. $2^{\mathrm{a}}$ ed. LTC, Rio de Janeiro, 2011.

[6] GOPAKUMAR, R.; TAKARA, K. Water Level Forecasting in the Vembanad Water System Using Artificial Neural Networks. In: International Conference on Advances in Recent Technologies in Communication and Computing, Washington, DC, USA. Proceedings... IEEE, 2009.

[7] GOMES, L. F. C., MONTENEGRO, S. M. G. L., VALENÇA, M. J. S. Modelo Baseado na Técnica de Redes Neurais para Previsão de Vazões na Bacia do Rio São Francisco. Revista Brasileira de Recursos Hídricos, 15(1), 05-15, 2010.

[8] NAPOLITANO, G., SEE, L., CALVO, B., SAVI, F., HEPPENSTALL, A. A conceptual and neural network model for real-time flood forecasting of the Tiber River in Rome. Physics and Chemistry of the Earth, Parts A/B/C, v. 35 , n. 3-5, p. 187-194, 2010.

[9] ADNAN, R., RUSLAN, F. A., SAMAD, A. M., ZAIN, Z. M. Artificial neural network modelling and flood water level prediction using extended Kalman filter. In: International Conference on Control System, Computing and Engineering, Penang, Malaysia. Proceedings... IEEE, 2012.

[10] XIE, J. C., TIAN-PING, W., JIAN-LONG, Z., SHEN, Y. A Method of Flood Forecasting of Chaotic Radial Basis Function Neural Network. Intelligent Systems and Applications (ISA), 2010.

[11] HAYKIN, S. Redes Neurais: princípios e prática. $2^{\mathrm{a}}$ ed. Bookman, Porto Alegre, 2001.

[12] SHULT, I., RUDOLPHO, L. S., GHODDOSI, S. M., NOLL, J. F., BACK, C. C., KONDLATSCH, K. M. S. Planejamento Territorial e Recursos Hídricos: As Áreas Protegidas no Entorno de Corpos de Água na 
Estudo Comparativo entre as Redes Neurais Artificiais MLP e RBF para Previsão de Cheias em Curto Prazo.

Bacia Hidrográfica do Rio Itajaí (SC). In: XX Simpósio Brasileiro de Recursos Hídricos, Bento Gonçalves - RS, 2013. Anais... Bento Gonçalves, 2013.

[13] CORDERO, A.; MOMO, M. R.; SEVERO, D. L. Previsão de cheia em tempo atual com um modelo armax, para a cidade de Rio do Sul-SC. In: XIX Simpósio Brasileiro de Recursos Hídricos Maceió - AL, 2011. Anais... Maceió, 2011.

[14] DORNELLES, F. Previsão contínua de níveis fluviais com redes neurais utilizando previsão de precipitação. Dissertação (Mestrado em Recursos Hídricos e Saneamento Ambiental), Universidade Federal do Rio Grande do Sul, Porto Alegre, 2007.

[15] BAKSHI, S.; BHAR, K. K. Estimation of Discharge in Rivers using ANN Modeled Rating Curves. Journal of The Institution of Engineers (India). Series A, v. 93, n. 3, p. 181-186, 6 mar. 2013. 